\title{
A Mixed-Method Analysis of an Equine Complementary Therapy Program to Heal Combat Veterans
}

\author{
Ellen Kaye Gehrke*1, Paul Tontz ${ }^{2}$, Ritika Bhawal ${ }^{3}$, Patric Schiltz ${ }^{1}$, Sarah Mendez ${ }^{3}$ and Michael P Myers ${ }^{1}$ \\ ${ }^{1}$ Department of Health Sciences, School of Health and Human Services, National University, USA \\ ${ }^{2}$ Department of Nursing, School of Health and Human Services, National University, USA
}

${ }^{3}$ Deparment of Community Health, School of Health and Human Services, National University, USA

Submission: September 29, 2018; Published: November 02, 2018

*Corresponding author: Ellen Kaye Gehrke, School of Health and Human Services, National University, San Diego, CA, USA

\begin{abstract}
This study presents a mixed-methods analysis to understand the healing experiences of veterans diagnosed with post-traumatic stress disorder (PTSD) in a heart-centered complementary therapy horsemanship program. This therapy was designed to address PTSD symptoms and involved weekly activities involving small group and one-on-one interactions with a horse and riding instructors. Previous work by our group found that this program provided significant improvement in the psychophysiological health of the participants. In this stage, the following research question was addressed: How did the veterans describe their healing experiences with horses in the program? A cohort of 9 combat veteran participants were first analyzed using the positive and negative affect schedule (PANAS) before and after each weekly session of the 8-week program. The PANAS results revealed a significant change in positive affect starting in week 2 (paired $t$ test, $t=-2.76, P=0.025$ ). Weekly writings from participant's journals were analyzed qualitatively using a phenomenological method of inquiry. This analysis resulted in a narrative integration of the significant statements, formulated meanings, and a cluster of themes. The themes centered around positive impact, connection with a horse, being present, horse mirroring, translating, trauma, and power dynamics. These themes described positive behaviors that resulted in reduced PTSD symptomology and promoted the healing phenomenon.
\end{abstract}

Keywords: PTSD symptoms; Veterans; Horsemanship; PANAS; complementary treatment; Mix-methods research; Equine assisted therapy

Abbreviations: PANAS: Positive and Negative Affect Schedule; PTSD: Post Traumatic Stress Disorder; EPE: Equine Partnered Experiences; TBI: Traumatic Brain Injury; HRV: Heart Rate Variability; HOH: Heart of Horsemanship program; DSM-5: Diagnostic and Statistical Manual of Mental Disorders, Fifth Ed.; PCL-5: PTSD Checklist for DSM-5; SSNI: Serotonin-Norepinephrine Reuptake Inhibitors; EMDR: Eye Movement Desensitization Reprocessing

\section{Introduction}

\section{PTSD}

There are more than 500,000 veterans who participated in various US military wars over the past 60 years who suffer from symptoms diagnosed as PTSD and traumatic brain injury (TBI). It is becoming clear that military personnel exposed to combat operations are at an increased risk for PTSD [1]. According to Makinson \& Young [2], "PTSD is a mental disorder characterized by a sudden onset of symptoms due to environmental exposure to a psychologically stressful event such as war, natural disaster, or sexual victimization". The DSM-5 handbook describes intrusion symptoms, avoidance, negative alterations in cognition and mood, and alteration in alertness and negativity [3]. Intrusion symptoms include the reoccurrence of the event in thoughts, dreams, illusions, or flashbacks. Those suffering from PTSD will also avoid thoughts and feelings connected to the event/people or places that trigger recollections of the trauma and possess negative alterations to include negative beliefs about oneself, diminished interest in social activities, or detachment from others. Veterans will express alteration in alertness and activity and exhibit irritable behavior, insomnia, and hypervigilance. Most importantly is that veterans who suffer from the impacts of PTSD experience an overall impairment in their day-to-day living.

\section{Treatment options}

In 2010, the Department of Veterans Affairs and Department of Defense released their recommended guidelines for treatment of PTSD. Of many modalities for treatment, exposure therapy, specifically prolonged exposure therapy, was recommended as an evidence-based treatment option. Other modalities included: cognitive processing therapy, stress inoculation training, treatment with Serotonin-Norepinephrine Reuptake Inhibitors (SSRI), and eye movement desensitization reprocessing (EMDR) treatment [4]. Until recently, equine therapy has not been the center stage of treatment options available for veterans. 


\section{Previous research}

The authors have been conducting research with military veterans since 2015 using equine therapy as a nonpharmacological complementary approach to healing. The first research stage employed a quantitative assessment measuring Heart Rate Variability (HRV) to determine the physiological changes occurring during a heart-based equine therapy program. Veterans were also given a psychological self-assessment to determine a positive and negative affect schedule (PANAS) of their equine experience. Results were significant from the quantitative perspective demonstrating a positive wellbeing outcome for the participants [5]. To endeavor in further inquiry, the authors shifted their emphasis to a mixed-method analysis based on the data from weekly journaling and recorded observations.

\section{History of healing veterans with horses}

Since the fifth century B.C. horseback riding was used for rehabilitating wounded soldiers [6]. For many years, animals have been used for the therapeutic benefit of humans in a variety of settings. For example, domestic animals are used to help medically ill children in hospitals and the elderly in nursing homes, but it was not until the 1960s that horses were used in the United States for therapeutic purposes [7]. Horses have proven effective in working in partnership with humans to aid the process of healing from trauma, grief, depression, and other emotional challenges. Unlike humans, they are not capable of hiding their emotions. In fact, they are primarily emotional beings and respond to the stimuli produced by emotional energy which begins from the heart [8].

Horses have abilities to interact with and heal humans. Like humans, horses live in social herds. Horses are prey animals making them hypervigilant to the intentions of those in the environment for their survival. Horses are quick and instinctual in sensing the emotional field around them. This helps encourage veterans to develop trust, to operate with integrity and fairness and to be clear in communication and intention. Horses enable veterans to accept criticism and self-judgment. This had led to veterans experiencing less anxiety, stress, emotional upheavals and feeling more confident in the decisions they make [5]. Experiences with horses provides a safe place for addressing and shifting the pain and suffering associated with PTSD.

\section{Materials and Methods}

The study was conducted in the fall of 2017 in one eightweek session. It took place at a small horse ranch in San Diego County, California. An IRB approval was acquired through National University which ensured no humans or animals were harmed in any way as part of the research. The primary focus was to assess whether equine assisted therapy and/or equine partnered experience would result in a reduction in symptoms associated with PTSD in American military veterans. The focus was on qualitative indicators from researcher observations and where veterans described, in journal format, their healing journey during the eight-week program. Measured psychophysiological findings were significant and a paper was published in the Military, Veterans and Family Health Journal [5] regarding the quantitative results. This paper provides an emphasis on the qualitative analysis relating to the deeper human aspect of what the experience meant to the veterans as they developed strong bonds and partnerships with the horses and as a group.

\section{Participant selection}

The participants were recruited from a Southern California Veterans center. The director of the Veterans Center was instrumental in identifying candidates who were working with traditional counseling therapy either in group or individually and referred them to the horsemanship program. Space was limited to nine in the cohort and the study team did not discriminate based on gender, age, or which war situation contributed to their PTSD. The ages ranged from 22 to 68 years and from Iraq to Vietnam deployments. We purposely did not request their PCL-5 [10] checklist scores or have them take any of the VA assessments regarding their level of PTSD.

All participants signed liability releases, consent forms, and photo release forms. They were informed regarding the research protocol and had the option to not participate. However, all were eager to participate and agreed to the weekly data collection that included taking a positive and negative affect instrument known as the PANAS (a validated instrument) [10] to determine if they would self-report improvements in symptoms associated with PTSD because of participating in the heart of horsemanship partnership program.

\section{Study design}

The study was conducted over eight weeks with one half day session each week. Participants arrived at the ranch in a van from the Vet Center or separately in their own vehicle. Upon arrival they would complete the 20 question PANAS questionnaire. The wranglers/instructors, veterans and two researchers would meet for about half hour in a circle to brief the group for the day's suggested activities. Each week included an opening circle and meditation where participants checked in. Participation was voluntary but most offered reflections of their current psychological state. The meditation focused on attentiveness of the heart and their body. A crystal bowl tuned to the heart was played to conclude the opening circle and then the veterans left the circle to go bond with and halter their horse. The sessions ran from 9 am to 12 noon, with two hours of horse engagement activities. We concluded with a closing circle at the end of each 3-hour session to allow for debrief and participant insight sharing. The crystal heart bowl was played as a final note and the veterans departed- often exchanging hugs and words with each other and the wrangler/instructors.

Specific symptoms associated with PTSD guided the curriculum design for each session and is outlined in Table 1. Each veteran initially selected their own horse based on a perceived felt energetic connection. They continued working with their selected horse on a continuous weekly basis. Participants also had an experienced individual wrangler/instructor who helped guide them in getting acquainted with their horse and to ensure their learning and safety. Sometimes veterans would join in all- 
group activities such as obstacle training, and other times they would work privately with their wrangler/instructor. The goals/

intentions of the weekly sessions were known and how each veteran addressed them varied from individual to individual.

Table 1: The Program/Intervention Design.

\begin{tabular}{|c|c|c|c|}
\hline Week & Goal/Intention & Targeted PTSD Symptom & Group Activities \\
\hline \multirow{3}{*}{1} & \multirow{3}{*}{ Establishing/building trust } & \multirow{3}{*}{ Lack of Trust/Isolation } & Meeting/Grooming \\
\hline & & & “Mutual Choosing”, Learning \\
\hline & & & horse language \\
\hline 2 & Building Connection/Presence & Anxiety & Grooming, Groundwork/Round Pen/Lock-on \\
\hline 3 & Sustaining Connection/Awareness & Relationship Issues & Grooming, Groundwork/ Round pen/ leading Activity \\
\hline 4 & Working Together/Flow & Anxiety & $\begin{array}{c}\text { Grooming, Groundwork/Round Pen, Leading, Saddling } \\
\text { Preparation }\end{array}$ \\
\hline 5 & Opening Heart/Managing Fear & Dissociation & $\begin{array}{c}\text { Grooming, Groundwork, Round Pen, Leading, Saddling, } \\
\text { Mounting, Riding (walk) }\end{array}$ \\
\hline 6 & Energetic Heart Synergistics & Irritability & $\begin{array}{c}\text { Grooming, Groundwork, Round Pen, Leading, Saddling, } \\
\text { Mounting, Riding (walk), Obstacles }\end{array}$ \\
\hline 7 & $\begin{array}{l}\text { Somatically Enhancing Mindfulness/ } \\
\text { Performance }\end{array}$ & Negative Beliefs and Detachment & $\begin{array}{l}\text { Grooming, Groundwork, Round Pen, Leading, Saddling, } \\
\text { Mounting, Obstacles, Riding (trot/canter) }\end{array}$ \\
\hline 8 & $\begin{array}{l}\text { Recognizing Wholeheartedness/ } \\
\text { Mind, Body, Spirit }\end{array}$ & Hypervigilance and Social Isolation & $\begin{array}{l}\text { Grooming, Groundwork, Round Pen, Leading, Saddling, } \\
\text { Mounting, Obstacles, Riding (trot/canter), Team-Work, } \\
\text { Transitions }\end{array}$ \\
\hline
\end{tabular}

The purpose of this phenomenological study is to understand how the interaction with equine partnered experiences (EPE) helped veterans with PTSD heal. We addressed the following qualitative question: How did veterans with PTSD describe their healing experiences in a group structured heart-centered horsemanship program?

\section{Data analysis}

Analysis was guided by the research question, the structured weekly journal prompts, and Colaizzi's [11] phenomenological method of inquiry. There are seven procedural steps to Colaizzi's [11] method of data analysis which include:

a) Reading all the participant's weekly journal entries to acquire a feeling for them.

\section{Results}

\section{PANAS}

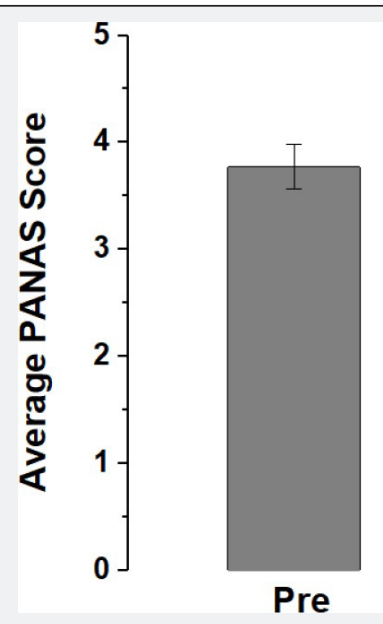

b) Extract significant statements from the transcriptions that are related to the veteran's self-reported healing process

c) Formulate meanings or codes from the significant statements.

d) Repeat step 3 for each participant's journals, and then place the codes into clusters of themes based on frequency.

e) Integrate all the results into an exhaustive description of the healing process and program.

f) Attempt to reduce exhaustive description into the unequivocal statement that is an identification of the fundamental structure of the phenomenon.

g) Return the findings to one participant in the study for inter-rater checking or informant feedback.

\section{PANAS}

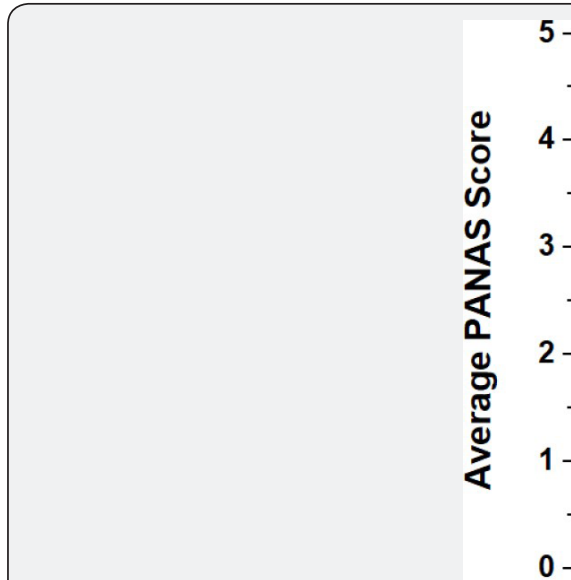

Figure 1: The change in affect pre and post program. 
For the PANAS results, the affect scores (negative affect converted to corresponding positive score) were averaged for the before (pre) and after (post) weekly sessions and are displayed as a bar graph in Figure 1. The subjects positive outlook improved over the course of the program. A significant change in affect occurred at week 2 using a paired test $(t=-2.76, \mathrm{P}=0.025)$ and stayed significantly different for the rest of the program $(t=-4.37$, $\mathrm{P}=0.002$ ). Week 1 showed improvement, but was not significantly different $(t=-2.00, \mathrm{P}=0.085$, data not shown).

\section{Qualitative coding meaning}

Based on a related study description of hospital-related fears for small children [12], the experience of a combat veteran with PTSD in a heart-centered equine partnered therapy program was outlined in Figure 2. These experiences in an equine therapy program consisted of essential curriculum components, the emotions and expressions elicited from the veterans, and the meaning associated with the experience.

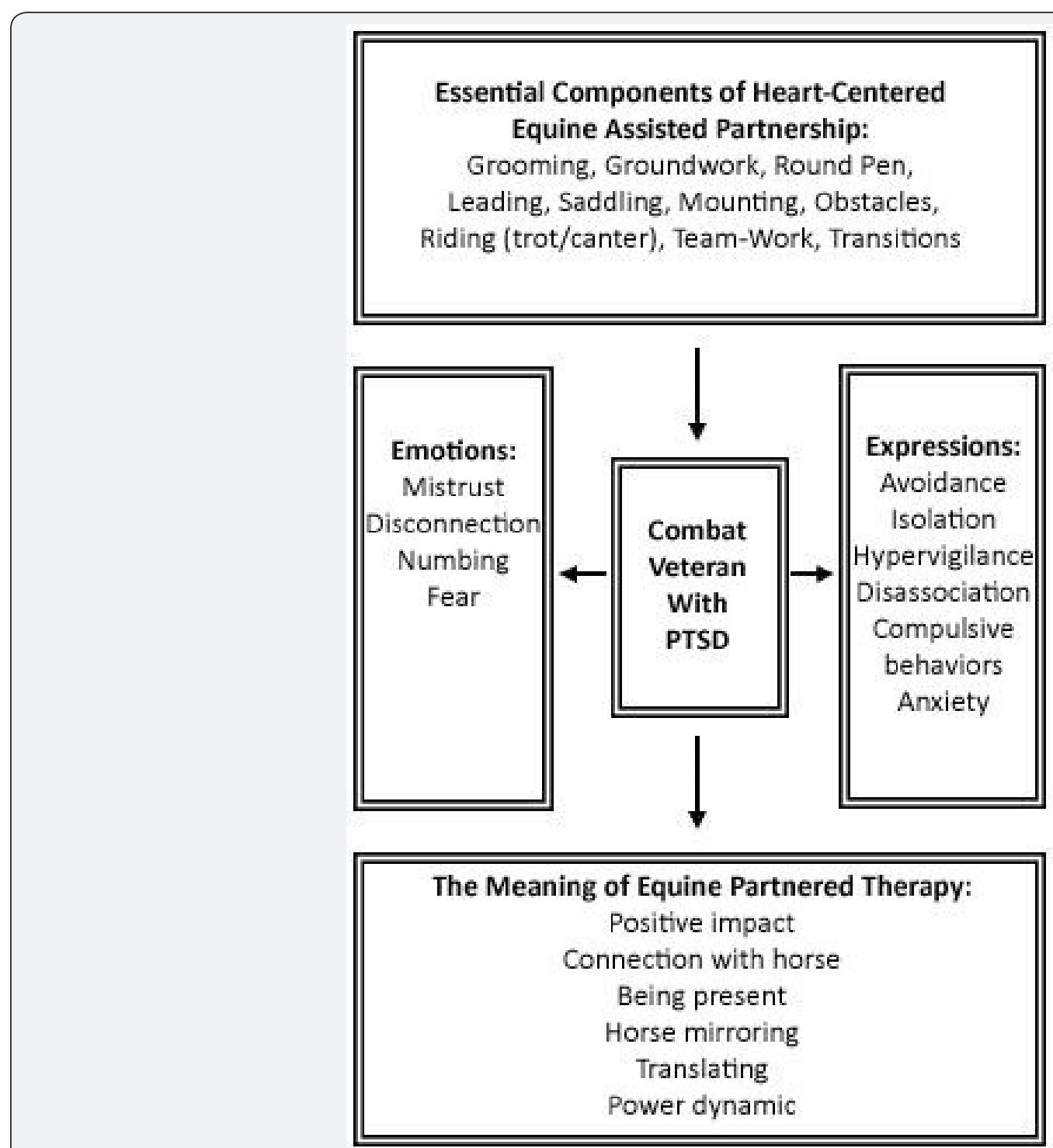

Figure 2: A description of a combat veteran's experiences in a heart centered equine therapy program.

\section{Essential components of heart-centered equine-assist-} ed partnership

This study intentionally designed heart-centered curriculum components to a heart-centered equine partnership around the symptomology of PTSD. These included activities such as grooming, groundwork, round-pen interactions, leading, saddling, mounting, managing obstacles, riding (trot/canter), teamwork exercises, and making riding transitions. These program components are described by week in Table 1 .
The ways in which combat veterans expressed themselves during the equine interaction

When each veteran interacted with their individual horse he or she described emotions of mistrust and feeling disconnected from the world. The veterans also described a feeling of emotional numbing, unable to express his or her feelings in their daily functioning.

Participants expressed themselves in behaviors related to avoidance and isolation, choosing to be alone with their horse 


\section{Journal of Complementary Medicine \& Alternative Healthcare}

versus with the group. They explain feeling outside of their bodies in a dissociative state disconnected from the present moment. Compulsive behaviors and being hypervigilant to those around

them and his or her surroundings were shared consistent with typical behaviors for the diagnosis of PTSD.

\section{The meaning of a heart-centered equine partnered experience to combat veterans with PTSD}

Table 2: The meaning of experiences in a heart centered equine therapy program for veterans with PTSD.

\begin{tabular}{|c|c|c|}
\hline Significant statements & Themes & Clusters \\
\hline $\begin{array}{c}\text { I knew it was going to be a different experience than what I expected and soon realized that it was } \\
\text { meant as a healing experience for Veterans with PTSD or other issues }\end{array}$ & Healing experience & Positive Impact \\
\hline \multicolumn{3}{|l|}{$\begin{array}{l}\text { I'm still in a state of awe, amazement, etc. and all positive from the equine therapy. It has shown me } \\
\text { so much without words. }\end{array}$} \\
\hline HOH has helped me see a greater need to bond with living creatures around me & $\begin{array}{l}\text { Need to bond with } \\
\text { people }\end{array}$ & \\
\hline $\begin{array}{c}\text { I intentionally try to let go of all the dirt and garbage from my life and bring joy, peace, and calm- } \\
\text { ness in as I approach }\end{array}$ & $\begin{array}{l}\text { Stay calm and less } \\
\text { anxious }\end{array}$ & \\
\hline $\begin{array}{c}\text { Because of the equine therapy I learned to focus and stays focused on the one task and clear my } \\
\text { mind of all other things. }\end{array}$ & Stay focused on task & \\
\hline I always feel much more upbeat and helpful after being at the ranch & State of happiness & \\
\hline I think the horses have been teaching me about communication, patience and calmness & $\begin{array}{l}\text { Communication and } \\
\text { patience }\end{array}$ & \\
\hline My connection with my horse is good so I can trust it & Trusting the horse & $\begin{array}{l}\text { Connection with } \\
\text { horse }\end{array}$ \\
\hline My horse and I did really good. Well, I was present and confident & $\begin{array}{l}\text { Confident and present } \\
\text { with my horse }\end{array}$ & \\
\hline I felt "in the zone" with my horse a decent amount & Felt in the zone & \\
\hline $\begin{array}{l}\text { What I learn is that when I'm with the horse, I'm thinking about nothing else. What a great lesson } \\
\text { to learn to be present with people and how complacent we become when we lose our fear }\end{array}$ & $\begin{array}{l}\text { When I am with horse, } \\
\text { not thinking of anything } \\
\text { else }\end{array}$ & Being present \\
\hline I finally feel connected with my horse when I "let go" and focus on her & $\begin{array}{l}\text { Need to stay focused and } \\
\text { present with my horse }\end{array}$ & \\
\hline $\begin{array}{c}\text { The week's prompt reminds me to stay mindful, as we say as therapists and really pay attention to } \\
\text { the words, feelings, expressions and body language of those around us }\end{array}$ & $\begin{array}{l}\text { Being with horse re- } \\
\text { minds me to stay mindful }\end{array}$ & \\
\hline $\begin{array}{c}\text { I learned more about the idea of connection than I thought I would, and about how much my mood } \\
\text { could affect my horse. When I started getting frustrated or checked out, my horse would essentially } \\
\text { do the same thing }\end{array}$ & $\begin{array}{l}\text { How much my mood can } \\
\text { affect my horse }\end{array}$ & Horse mirroring \\
\hline $\begin{array}{l}\text { My horse can't talk. But she does communicate in the sense that when I get distracted she ignores } \\
\text { me. I do notice that at times. }\end{array}$ & $\begin{array}{l}\text { If I am distracted my } \\
\text { horse ignores me too }\end{array}$ & \\
\hline I started to check out and the horse stopped responding to me as much or as well & $\begin{array}{l}\text { My horse pays attention } \\
\text { when I am focused }\end{array}$ & \\
\hline I find that the time I spend with my horse helps me to bond with people better & $\begin{array}{l}\text { Time I spend with horse } \\
\text { helps me bond with } \\
\text { people Started trusting } \\
\text { people as I }\end{array}$ & Translating \\
\hline $\begin{array}{l}\text { There were a few things I thought about today. It almost seems like I was able to start trusting the } \\
\text { people in the group a little more by trusting and feeling safe and confident with my horse }\end{array}$ & $\begin{array}{l}\text { become more trustful of } \\
\text { my horse }\end{array}$ & \\
\hline $\begin{array}{l}\text { I'm hoping that as time goes on I am able to think of equine therapy and apply it to my life when it } \\
\text { goes when it comes to people - especially the difficult ones }\end{array}$ & $\begin{array}{l}\text { Apply equine therapy to } \\
\text { human relationships }\end{array}$ & \\
\hline $\begin{array}{l}\text { I always would think of how these experiences related to humans...it is amazing how almost all of } \\
\text { the lessons helped me with my communications and appreciation of other people }\end{array}$ & Lack of trust in authority & Power dynamic \\
\hline $\begin{array}{l}\text { While he seems nice, I still don't feel totally safe with him, mainly because I'm so used to people in } \\
\text { authority (mainly the chaplains I worked for) screwing me over, that I'm somewhat afraid he will } \\
\text { do something too }\end{array}$ & $\begin{array}{l}\text { People in authority } \\
\text { impose their ways }\end{array}$ & \\
\hline $\begin{array}{c}\text { My only heartburn was: Each instructor/cowboy does things a little different, they want to see you } \\
\text { doing it their way only... "Only". That's not cool!! }\end{array}$ & & \\
\hline
\end{tabular}


The meaning of an equine-partnered experience for combat veterans with PTSD are defined by several significant statements that consisted of six main clusters that came out of the qualitative analysis: positive impact, connection with horse, being present, horse mirroring, translating, and power dynamics (Table 2).

\section{Positive impact}

The cluster of positive impact consisted of six themes describing an overall positive impact of participation. The theme of healing experience describes how many of the veterans found interaction with his or her horse to be a healing process. The program also reaffirmed veterans need to bond with people. and find connection. Staying calm and less anxious were intentionally challenged to help the veteran find more peace, joy and calmness to the experience, but also to their lives. Intention to focus on task helped clear the veterans mind from other distractions in his or her life. Finally, themes of communication and patience and overall state of happiness were evident as the horse interaction allowed the veteran to better communicate and provide an overall sense of peace and happiness.

\section{Connection with horse}

The feeling of connection is one that many of us strive for. Both horses and humans are social species, seeking connection to others is an important part of our emotional and physical well-being. Connection is a feeling, and so it can be described in different ways. Veterans describe this connection as an awareness of a presence with a sentient being. They describe that having a connection allows them to trust his or her horse. And participants feel accomplished when they are present and confident in their ability with the horse. Over the course of the program, veterans explain feeling in the "zone" in which they felt a oneness oftentimes without thinking or trying too hard to do so.

\section{Being present/mindfulness}

The cluster being present/mindfulness explains how the veteran felt grounded, in the moment and totally focused on the present moment. For example, when committed to the entire presence and behavior of the horse, the veteran forgets about other stressors or anxieties in his or her life. They recognize that intentional focus on the horse, allows a "letting go" to be present around the horse. Reciprocally, being totally with the horse also seems to reinforce personal mindfulness of those others around him or her.

\section{Horse mirroring}

Horse mirroring is the reflection of self in the horse's emotions and behavior. In other words, if the veteran noticed his or her mood was poor the horse would respond accordingly poor. Also, if the veteran bought daily living distractions such as family or personal life into the interaction, the horse ignored the veteran. Soon the veteran realized that the horse pays attention when the combat veteran "shows up" to lead and is focused on the horse.

\section{Translating}

Applying program lessons to one's personal life was described in the cluster of themes as translating. In short, the veteran begins to translate little lessons learned in interacting together with the rest of his or her social world. Learning how to bond with the horse seemed to reinforce a positive bonding with people. Similarly, learning to overcome trust issues from his or her trauma, became evident when the participant wholeheartedly trusted their horse. Quite powerfully, the veteran changed psychosocially applying his or her thoughts and behaviors to their interaction with human relationships.

\section{Power dynamics}

Finally, for some veterans a cluster of themes around power dynamics existed, expressing relational distrust of authority figures such as the therapist, facilitators or wranglers. The veteran expressed their lack of trust in authority, and that people in authority impose their ways on them. The veteran had to change their rigid ideas of how to do things as directed by an authority figure, in this case the horse wranglers.

\section{Discussion}

The results offer a view of the experience and phenomena of a heart-centered, equine-assisted partnership for veterans diagnosed with PTSD. The PANAS results demonstrated a significant improvement in affect. In our last study [5], it took 4 weeks to see a significant change in affect. Here we have more evidence that it takes time (2-4 weeks) for the affect score to catch up to the immediate change in HRV. While veterans expressed behaviors and emotions consistent with a diagnosis of PTSD in the qualitative observations and journaling (isolation, hypervigilance, distrust, etc.) most participants shared positive outcomes of participation, explained in the cluster of themes. For example, the theme of positive impact defined by the ways in which the participants experienced a favorable, helpful, beneficial outcome of the program was consistent with Earles, Vernon, and Yetz' study [13] that showed Equine Partnering Naturally (c) programming may be an effective treatment for anxiety and posttraumatic stress syndrome for veterans with PTSD.

Similarly, participants defined and expressed their connection with their horse. Some felt most connected when just standing or walking with the horse while some connected while grooming. The most common description of connection were moments of moving in unity, a feeling of oneness and togetherness. Horse to veteran connection has previously been documented in the Saratoga War Horse Project [14] in which the Connection methodology: nonverbal language of the horse in a predictable, sequential, and repeatable method was used with a combat veteran to build a horse-human connection with positive psychological functioning outcomes and reduced PTSD symptomology.

Horses, are highly social, nomadic prey animals. They embody many of the attitudes and skills that some humans spend their lives searching for. One of the pluses of being "in the moment" is the ability to act quickly in the face of danger, and sometimes more importantly, to be able to let it go and go back to grazing.

Participants spoke of "being an outsider looking in" and "losing touch with reality". This form of avoidance which presents itself 
as dissociation or emotional numbing is common for survivors of trauma [15].

Participants describe a realization in working with horses that to form connection, stay present, and manage dissociation they need to focus and concentrate on one thing at time. Zerubavel and Messman-Moore [16] summarized well these phenomena. Mindfulness is a strong treatment for dissociative behavior as it removes one from the present moment, while mindfulness cultivates the ability to stay in the moment.

Another cluster reported was horse mirroring. Zugich, Klontz, and Leinart [17] describe the horse as mirrors in which they can "provide accurate and unbiased feedback, mirroring physical and emotional states of the veteran, providing clients with the opportunity to raise their awareness and to practice congruence between their feelings and behaviors". Veterans describe a lack of presence impacted his or her horse's behavior, providing real time feedback helping the veteran autocorrect and stay present with both his or her feelings and behaviors.

One of the most salient findings of the study was the way in which participants transferred their learning from the program and his or her horse and hoped to use the new awareness in their lives. A parallel study [18] using outdoor based adventure experiences to treat veterans with PTSD found similar findings regarding veterans' renewed ways of translating the experience to their relationships. This is similar to a recent equine related study [19] for student veteran nursing students who translated interactions with horses to their personal and academic lives.

Finally, an unexpected finding was concern around power and authority as veterans described a lack of trust and frustration at times with the supervising clinical therapist and wranglers involved in the group facilitation. Johnson and Lubin [20] argue that this type of transference reaction to clinical leadership will also reflect past experience with authority especially relative to the trauma. And this lack of trust in authority and intolerance of imperfection is documented in Alford, Mahone \& Fielstein's [21] work with Vietnam veterans with PTSD. Alternatively, some participants respected and trusted authority, consistent with Turchik and Wilson's [22] research on military obedience to authority.

\section{Special considerations}

Moving forward it's crucial that health care practitioners and educational institutions be trained in cultural competency to understand veteran populations. What may seem like a defiance of instruction might be a lifesaving way of "being" to a veteran. One veteran described his frustration in being asked to look forward in working with his horse instead of at his feet. Researchers learned later he had worked in explosives detection and his squad's lives were dependent on his looking down. He had carried this attitude with him into his civilian way of being. Atuel and Castro [23] provide a strong overview of military cultural competency to include military culture as it applies to therapeutic work for veterans.

\section{Conclusion}

In conclusion, the goal of this study was to explore the qualitative aspects of a heart-centered equine therapy program. Previous work by the authors showed psychophysiological improvement in veterans participating in the 8- week program [5]. The PANAS results showed a significant improvement in affect in the participants by the second week of the program. A qualitative evaluation of the participants journal entries and research observations revealed six clusters associated with the meaning of a heart centered equine assisted partnership. The combat veteran with PTSD may experience differing levels of interaction and change in working with an equine partner. His or her positive impact may be leveraged by the ability to connect with the horse, staying present, and translating the learnings to interactions with people. More negative expressions and behaviors due to PTSD may be observed regarding questioning authority figures and the symptomology related to trauma such as distrust, social anxiety, isolation and hypervigilance.

The veteran came to recognize that his or her affect and behavior is directly reflected or mirrored in the horse's behavior, such that the combat veteran became self-aware of his or her attitudes and behaviors and self-corrected to create a stronger bond with their horse. Thus, the phenomenon of equine partnership creates psychosocial, physical, and emotional changes that may serve as a non-pharmacological approach to treatment for PTSD.

\section{References}

1. Hoge C, Auchterlonie J \& Milliken C (2006) Mental health problems, use of mental health services, and attrition from military service after returning from deployment to Iraq or Afghanistan. JAMA 295(9): 10231032.

2. Makinson R \& Young S (2012) Cognitive behavioral therapy and the treatment of posttraumatic stress disorder: Where counseling and neuroscience meet. J Couns Dev 90(2): 131-141.

3. American Psychiatric Association (2013) Diagnostic and statistical manual of mental disorders, (5th ed.). Washington, DC: Author.

4. Department of Veteran Affairs \& Department of Defense (2010) VA/ DoD clinical practice guideline for management of posttraumatic stress.

5. Gehrke EK, Noquez AE, Ranke PL \& Myers MP (2018) Measuring the psychophysiological changes in combat Veterans participating in an equine therapy program. J Mil Vet Fam Heal 4(1): 60-69.

6. Gamache J (2004) Equine assisted therapy's effect on social skills and attention among school age children. Paper for University of Puget Sound, Tacoma, WA

7. Hayes T (2016) Riding home, the power of horses to heal. St. Martins Griffin.

8. Gehrke EK (2010) The Horse-Human Heart Connection, Results of Studies Using Heart Rate Variability. Narha's Strides pp. 20-23.

9. Weathers FW, Litz BT, Keane TM, Palmieri PA, Marx BP (2013) The PTSD Checklist for DSM-5 (PCL-5). Scale available from the National Center for PTSD.

10. Watson D, Clark LA, Tellegen A (1988) Development and validation of brief measures of positive and negative affect: the PANAS scales. J Pers 
Soc Psychol 54(6):1063-1070.

11. Colaizzi PF (1978) Psychological research as the phenomenologist views it. In: Valle R \& King M (Eds.), Existential Phenomenological Alternatives for Psychology. Oxford Press, New York, USA, pp.48-71.

12. Salmela, M, Aronen, E, \& Salantera, S (2010) The experience of hospital-related fears of 4-to-6 year old children. Child: Care, health and development 37(5): 719-726.

13. Earles J, Vernon L, \& Yetz J (2015) Equine-assisted therapy for anxiety and posttraumatic stress symptoms. J Trauma Stress 28(2): 149-152.

14. Nevins R, Finch S, Hickling EJ \& Barnett SD (2013) The Saratoga WarHorse project: A case study of the treatment of psychological distress in a veterans of Operation Iraqi Freedom. Advances in Mind Body Medicine 27(4): 22-25.

15. Banks K, Newman E, Saleem J (2015) An overview of the research on mindfulness-based interventions for treating symptoms of posttraumatic stress disorder: A systematic review. J Clin Psycho 71(10): 935-965.

16. Zerubavel N, Messman-Moore TL (2015) Staying present: incorporating mindfulness into therapy for dissociation. Mindfulness 6(2): 303-314.

This work is licensed under Creative Commons Attribution 4.0 License

DOI: 10.19080/JCMAH.2018.08.555739
17. Zugich M, Klontz T \& Leinart D (2002) The miracle of equine therapy Counselor Magazine 3(6): 22-27.

18. Hyer L, Boyd S, Scurfield R, Smith D, Burke J (1996) Effects of outward bound experiences as an adjunct to inpatient PTSD treatment of war veterans. J Clin Psychol 52(3): 263-278.

19. Voelpel P, Escallier L, Fullerton J, Abitbol L (2018) Interaction between veterans and horses: Perceptions of benefits. J Psychosoc Nurs Ment Health Serv 56(5): 7-10

20. Johnson D, Lubin H (2000) Group psychotherapy for the symptoms of posttraumatic stress disorder.In Klein RH, Schermer VL (Eds.), Group Psychotherapy for Psychological Trauma. New York: The Guilford Press pp.141-169.

21. Alford JD, Mahone C, Fielstein EM (1988) Cognitive and behavioral sequelae of combat: Conceptualization and implication for treatment. Journal of Traumatic Stress 1(4):489-501.

22. Turchik JA, Wilson SM (2010) Sexual assault in the U.S. military: A review of the literature and recommendations for the future. Aggress Violent Beh 15(4): 267-277.

23. Atuel HR, Castro C (2018) Military cultural competence. Clin Soc Work J 46(74)

\section{Your next submission with Juniper Publishers} will reach you the below assets

- Quality Editorial service

- Swift Peer Review

- Reprints availability

- E-prints Service

- Manuscript Podcast for convenient understanding

- Global attainment for your research

- Manuscript accessibility in different formats

( Pdf, E-pub, Full Text, Audio)

- Unceasing customer service

Track the below URL for one-step submission https://juniperpublishers.com/online-submission.php 